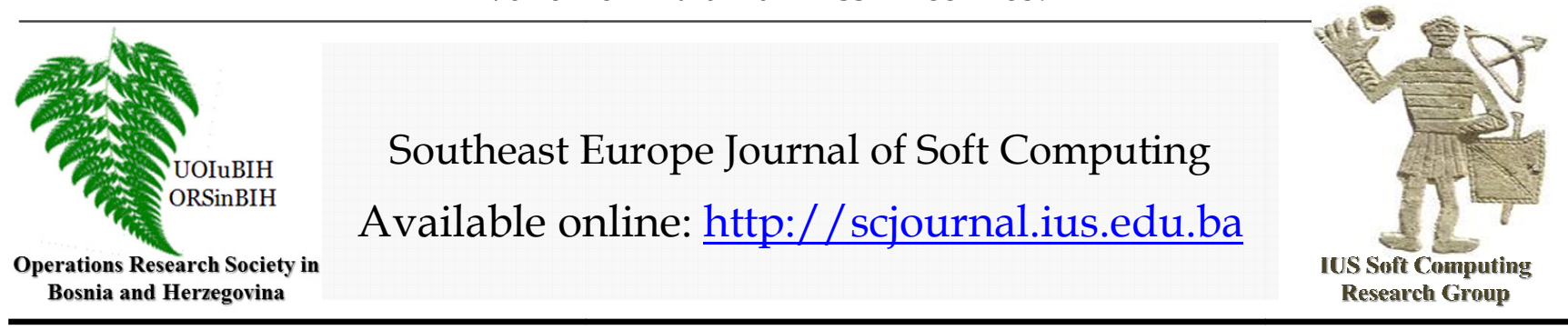

\title{
Continuous-time Markov chain in labor market theory: The case of United Kingdom
}

\author{
Narela Spaseski \\ International University of Sarajevo, \\ Faculty of Business and Administration, \\ HrasnickaCesta 15, Ilidža 71210 Sarajevo, \\ Bosnia and Herzegovina \\ narela7@yahoo.com
}

\section{Article Info}

Article history:

Article received on 11 Jan. 2017 Received in revised form 27 Feb. 2017

Keywords:

Continuous-time Markov chain, UK labour market, transient analysis.

\begin{abstract}
In this paper, the claim that the sojourn times in the UK labor market follow a continuous-time Markov model is investigated. It means that they are independent random variables and mainly they control how rapidly transits take place. In this case sojourn times in a state before they transit another state are exponentially distributed with an appropriate parameter $\lambda_{i}$.

The labor market model presented in this paper is based on Markov process techniques and have been developed in Wolfram Mathematica 9. The model allows us to calculate the long-run proportion of workers transitions, first-passage time and the transition state probabilities. These parameters are then used to detect labour market failures and accordingly propose policies and procedures that Government can use to build a more efficient labour market and increase employability.
\end{abstract}

\section{INTRODUCTION}

In this paper the labour market dynamics is viewed as a Markovian process with individuals moving between the three labour states, i.e. employed, unemployed and inactive. Often the exact time of the transits, the sojourn times are not known. Therefore, the probability of workers

staying in each state can be obtained by the proposed model, which can then be used to quantify the number of workers, and the rate of leaving the state $\left(\lambda_{\mathrm{ij}}\right)$, respectively. Other equally important reason of applying this model in practice is the use of the memoryless property which makes it easy to reason about the average exponentially distributed transits in the labor markets.

The labor market behavior in a continuous-time Markov chain is defined by a stochastic process $Y=\{Y(d): 0 \leq d\}$ with finite or countable state space $S=\{1,2,3\}$. By definition, the stochastic process has the Markov property if

$$
P\left\{Y(d)=j \mid F_{y(s)}\right\}=P\{Y(d)=j \mid Y(s)=i\}
$$

where $\mathrm{F}_{\mathrm{y}}(s)$ stands for entire information belonging to the history of $\mathrm{Y}$ from 0 up to time s, and letting $i, j \in \mathrm{S}$ and $0 \leq s \leq d$. Or it can be stated that the probability of being in state $j$ at time $d$, given that the system was in state $s$ at time 
$d$ and the entire history of states, is equal to the probability without the information on the entire history.

The Markov processes can have the following three properties: homogeneity, reversibility and stationarity. Accordingly, the homogeneous process has an equilibrium distribution which is the stationary (limiting) distribution when time approaches to infinity. For a continuous- time homogeneous Markov chain $\mathrm{Y}(\mathrm{d})$, the transition probability function for $\mathrm{d}>0$ is:

$$
P\{Y(d)=j \mid Y(s)\}=P\{Y(d-s)=j \mid Y(0)=i\}
$$

Meaning, each time the process enters statei, the way it behaves probabilistically is same as if the process started in state iat time 0 . Here, the time it spends in state $i$ before it leaves it is the same every time and is known as the waiting(sojourn) time.

The sojourn times of a continuous-time Markov model are independent random variables and mainly control how rapidly the transit takes place. They are exponentially distributed with parameter $\lambda_{\mathrm{i}}$, so the probability of transition from a particular state $i$ to another state before a time $\mathrm{x}$ is given by

$$
\begin{aligned}
F(x)=P\{s \leq x\} & =\left\{\begin{array}{ll}
0 & \text { if } x \leq 0 \\
1-e^{-\lambda_{i} x} & \text { if } x>0
\end{array}, i\right. \\
& =1,2, \ldots, 6
\end{aligned}
$$

$F(x)$ in (3) is the cumulative probability function for the density function

$$
f(x)= \begin{cases}0 & \text { if } x \leq 0 \\ \lambda_{i} e^{-\lambda_{i} x} & \text { if } x>0\end{cases}
$$

Using a built in fit function in the computer algebra package MATHEMATICA Rates $\lambda_{i}$ are computed for all of the six sojourn times, that is waiting times in state $i$, before transition to another state.

The exponential distribution is the only continuous memoryless probability distribution. Because of the memoryless property, the length of time a person has stayed in a particular state in the past, has no impact on its future behavior, so as seen in the equation below the probability that the person fails to transit in the near future is always the same and doesn't depend on its current age in that state.

$$
P(Y>x+d \mid Y>d)=P(Y>x)
$$

In other words, if the time between transits is exponentially distributed, the memorylessness property tells us that our waiting times are of no use in prediction when the next transit will take place.
It is also important to point out that the probability of transition from state ito state $j$ is also exponentially distributed but with parameter $\mathrm{q}_{\mathrm{ij}} \geq 0$. According to their definition one has,

$$
\sum_{j \neq i} q_{i j}=\lambda_{i}
$$

and $q_{i j}$ are known as transition rates, hazard rates or exit rates. Therefore, the hazard rate for leaving the state $i$ to another state $j$ is the probability density function PDF of the duration $\mathrm{f}(\mathrm{d})$ divided by the survival function of the state $i, 1-\mathrm{F}(\mathrm{t})$;

$$
h(d)=\frac{f(d)}{1-F(d)}=\frac{\lambda_{i} e^{-\lambda_{i} d}}{e^{-\lambda_{i} d}}=\lambda_{i}
$$

The continuous-time Markov model is governed by a transition intensity matrix, also known as a generator matrix $\mathrm{Q}(\mathrm{d})$, such as:

$$
\mathrm{Q}(\mathrm{d})=\left[\begin{array}{ccc}
-q_{12}(d)-q_{13}(d) & q_{12}(d) & q_{13}(d) \\
q_{21}(d) & -q_{21}(d)-q_{23}(d) & q_{23}(d) \\
q_{31}(d) & q_{32}(d) & -q_{31}(d)-q_{32}(d)
\end{array}\right]
$$

For the labor markets, there are three possible states through which the people can transit, corresponding to employed (E), unemployed (U) and inactive (I). Transitions into all states are permitted. The graphical presentation of the model is given in Figure 1, and we have:

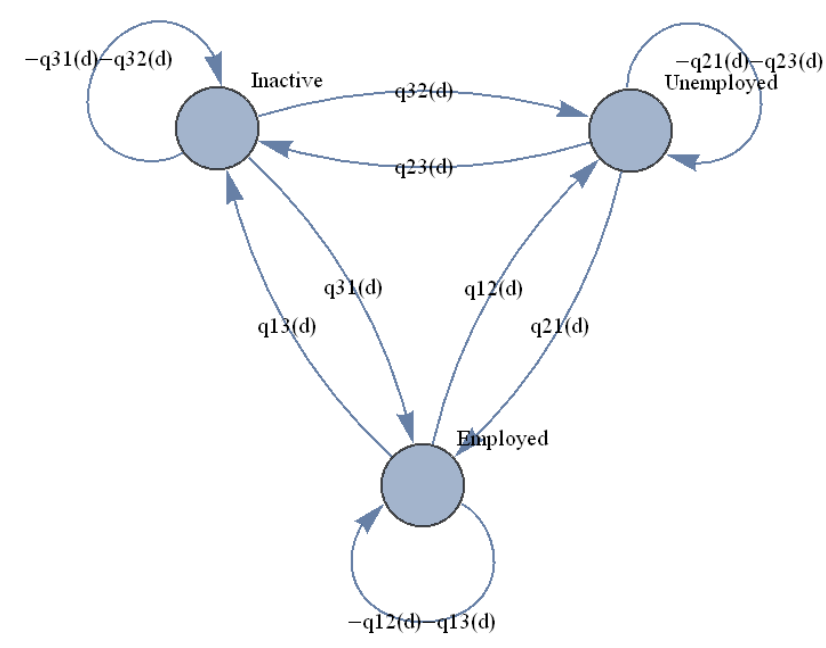

Figure 1. Transition in UK labour market with $q_{i j}$ intensity rates 


\section{N. Spaseski/ Southeast Europe Journal of Soft Computing Vol.6 No.1 March 2016 (13-19)}

What is more, the intensity matrix $Q(d)$ must satisfy the following criteria:

- The off diagonals (rates at which people transit) must be non-negative, $q_{i j}(d) \geq 0$ for $i \leq I, j \leq K$ with $\mathrm{i} \neq \mathrm{j}$

- $\quad$ The rows must sum to zero, $\sum_{j=1}^{K} q_{i j}(d)=0$, for $1 \leq \mathrm{i} \leq \mathrm{I}$

- $\quad 0 \leq-\mathrm{q}_{\mathrm{iii}}=\mathrm{q}_{\mathrm{i}} \leq \infty$, for $1 \leq \mathrm{i} \leq \mathrm{I}$

Here the intensity rate $\mathrm{q}_{\mathrm{ij}}(\mathrm{d})$, can be understood as the rate of change of the probability $\mathrm{P}_{\mathrm{ij}}$ in a very small time interval, $\Delta \mathrm{d}$, or

$$
q_{i j}(d)=\lim _{\Delta t \rightarrow 0} \frac{P_{i j}(d, d+\Delta d)}{\Delta d} i \neq j
$$

Where $P_{i j}$ is the probability that the system which is initially in state $\mathrm{i}$ will be in state $\mathrm{j}$ at $\mathrm{d}$, and $\Delta \mathrm{d}$ is the time interval length.

\section{LITERATURE REVIEW}

The standard approach in labour economic literature discusses the discrete-time Markov chains where the population is divided into three labour market states as employed (E), unemployed (U), and inactive (I). Here researchers compare changes in workers' status between two discrete periods usually a month, quarter, or a year. Based on this information they create the matrix of transition probabilities, where the rows show the workers labour market status in an initial period and the columns show the status of the same worker in future.

One of the first papers applying this labour flows analysis in practice are those of Mincer (1966), Toikka (1976), Marston (1976), Clark et.al (1979), Burdett and Mortenscn (1980), Flinn and Heckman (1982b), Coleman (1984), Mortensen and Neumann (1984), Weiner (1982), Abowd and Zellner (1985).

Moreover, several significant studies have demonstrated that the analysis of labour worker flows as well as the job flows delivers important understandings above analysis of the unemployment rate. Here we can mention the papers of Blanchard et.al. (1990), Blanchard and Diamond (1992), and Davis and Haltiwanger (1990,1999).

These empirical analyses have been accompanied by theories of job flows and workers' flows, as those have been presented in the papers of Pissarides $(1986,1991)$, Mortensen\&Pissarides (1994), Hall (2005), and Shimer (2005).

Furthermore, we have the papers of Elsby et al. (2009), Shimer (2007) and Petrongolo\&Pissarides (2008). They show how the construction of unemployment flows in and out of the unemployed state allows cross-country comparisons of labour market dynamics.

The main drawback of the discrete-time approach is that in real life situation observations are influenced not just at a single instant but through the entire interval of time. In particular, the discrete-time Markov chain can tell us nothing about where those workers arrived from, their waiting time/sojourn times, or where they will go later.

The second part of this review outlines the application of continuous-time Markov process.

An interesting application of continuous-time Markov chain is given by Bascetto et.al. (2009). They compare labour market dynamics in two populations: individuals diagnosed with breast cancer and individuals without breast cancer. In other words, they studied the impact of breast cancer on transitions between employment, nonemployment and retirement two years after diagnosis.

Bosch and Maloney (2005) apply the continuous-time Markov model to study the labour market dynamics of three developing countries: Argentina, Brazil and Mexico. They examine the flows of workers among five states: three types of paid labour, unemployment and out of the labour force.

One more excellent account of continuous-time Markov chain can be found in the paper of Tiongson and Fares (2007). They study the labour market transition, early unemployment spells and their long-term effects on youth in Bosnia and Herzegovina. Furthermore, Baussola and Mussida (2011) using CTMC showed that the unemployed gender gap is relevant within the Italian labour market. They also point out the inclusion of the inactivity state gives a more precise decomposing of the gender gap. In this sense, females do show both a notably lower probability of entry into labour force and even lower probability of exiting unemployment state and moving to employment state with respect to their male counterparts.

Other articles published in this field are those from Schettkat (2003), Fougere and Kamionka (2003),Aoki and Yoshikawa (2011), Fabrizi and Mussida (2009), Fujiwara and Aoyama (2010).

\section{DATA}

The first step in the construction of longitudinal dataset is matching records of labour market statuses (employment, unemployment, inactivity) for the same worker over a number of continuous surveys. In the labour force surveys', I look in two section of questions: the current period information and those who provides the retroacting information. By retroacting information, I refer to those relating to the duration in a particular state (sojourn times) and those related to the worker labour market status one year ago. This will help us to attain the following nine labour flow categories: UU, UI, UE, EE, EU, EI, II, IE and $\mathrm{IU}$, which are quantified by

$$
F_{d}^{S X}=\sum_{i \in G_{d}^{s x}} w_{i d}
$$


where $w_{i d}$ is the sample weight of the worker $i$ at year $d$, and $\mathrm{G}_{\mathrm{d}}{ }^{\mathrm{xy}}$ is the group of workers who transit from state $\mathrm{S} \in$ $\{\mathrm{E}, \mathrm{U}, \mathrm{I}\}$ to state $\mathrm{X} \in\{\mathrm{E}, \mathrm{U}, \mathrm{I}\}$ at year $\mathrm{d}$.

\subsection{United Kingdom}

The observation period is from $1^{\text {st }}$ January 1991 to $31^{\text {st }}$ of December 2009, based on British Household Panel survey: Waves 1-18, 1991-2009. The construction of longitudinal data set is done in Microsoft SQL Server 2014. Here, year 1991 is taken as a base year and those entering or leaving the workforce are left out from the measured sample. By definition, the dataset is longitudinal if it tracks the same type of information of the same person or subject, over a given time period. As a result, the sample data used in this thesis is balanced and made of 6795 people and 14.220 transits. The data includes the following information:

- The ID of the person (PID), the time when he/she enters into a particular state,

- the time when he/she leaves this state,

- activity status (employed, unemployed and inactive),

- waiting time in days (sojourn times),

- and censoring (0 stands for non-censored data and 1 for censored data). In particular, censoring is a condition in which the observation is only partially known. In our case the data is right censored; i.e. the data collection process ends before the event/transition has occurred.

And the matrix of frequencies of transitions between consecutive states calculate by Equation 1 is:

$\begin{array}{cccc} & E & U & I \\ E & 2930 & 1386 & 1734 \\ U & 1219 & 205 & 485 \\ I & 1839 & 523 & 908\end{array}$

(11)

Thus, there were 1219 transits to employed (E) from state unemployed (U), 1839 transits to employed (E) from state inactive (I), and 2930 subjects stayed in the state employed(E) during the data collection period.

\section{METHODOLOGY AND RESULTS}

In this paper I investigate the claim that the sojourn times in the labor market follow a continuous-time Markov model. It means that sojourn times in states before they transit another state are independent random variables and mainly they control how rapidly transits take place. In this case sojourn times in a state before they transit another state are exponentially distributed with an appropriate parameter $\lambda_{i}$.

To fit the continuous-time Markov model to UK labor flow data, sojourn times in states before they transit another state are estimated from the UK longitudinal data.
Using a Maximum Likelihood estimator (MLE)parameters $\lambda_{i}$ of appropriate exponential distributions are estimated.

$$
f\left(x ; \lambda_{i}\right)=\left\{\begin{array}{ll}
\lambda_{i} e^{-\lambda_{i} x} & \text { if } x \geq 0 \\
0 & \text { if } x<0
\end{array}, \quad i=1,2, \ldots, 9\right.
$$

Using a built in fit function in the computer algebra package MATHEMATICA Rates $\lambda_{i}$ are computed for all of the six sojourn times, that is waiting times in state $i$, before transition to another state.

$$
\Lambda=\left[\begin{array}{ccc}
- & 0.00026321 & 0.00018 \\
0.0001058 & - & 0.0005099 \\
0.000145734 & 0.000702 & -
\end{array}\right]
$$

As mentioned earlier, continuous-time Markov model is governed by a transition intensity matrix $Q(d)$ as in Equation 8. Using another built in fit function in the computer algebra package MATHEMATICA intensities $q_{i j}(d) \lambda_{i}$ are computed for all of the nine states:

$$
Q=\left[\begin{array}{ccc}
-0.00028442 & 0.000129797 & 0.000154645 \\
0.0021824 & -0.0035884 & 0.001406 \\
0.000627008 & 0.0003 & -0.000927008
\end{array}\right]
$$

Then first passage time probability density function, which is needed in the calculation of the state transition probabilities is determined. Using UK labour market flow data, transition probabilities between states are estimated

$$
P(0)=\left[\begin{array}{ccc}
0.940921 & 0.0261072 & 0.0329719 \\
0.325502 & 0.468185 & 0.206313 \\
0.124548 & 0.0563042 & 0.819148
\end{array}\right]
$$

Thus, given a person enters state 3 (inactive) at $\mathrm{t}=0$, he/she has a 0.0563 probability to be 1 year later in state 2 (unemployed), probability of 0.124548 to be 1 year later in state 1 (employed), and probability of 0.819148 being still in state 3(inactive).

$$
\begin{gathered}
>\text { Mean Sojourn Times (MST) in days } \\
\text { is: } \\
M S T=\left[\begin{array}{lll}
3515.66 & 3472.49 & 3456.098 \\
831.932 & 278.675 & 380.134 \\
2895.67 & 1502.396 & 1078.74
\end{array}\right]
\end{gathered}
$$

It describes the average period in a single stay in a state. 


\section{$>$ Expected First Passage Times (FPT) in days:}

$$
F P T=\left[\begin{array}{ccc}
1.31127 & 3320.935 & 2787.397 \\
197.92 & 22.8461 & 306.964 \\
687.807 & 1437.065 & 5.16504
\end{array}\right]
$$

FPT is the expected time until the process first enters a given state, also known as the hitting time. Thus, 198 days are needed for a transit from unemployed to employed state.

\section{$>$ Stationary distribution/long-run proportion is:}

$$
\begin{aligned}
\pi 1=0.762629 ; \\
\pi 2=0.0437697 ; \\
\pi 3=0.193602 ;
\end{aligned}
$$

The long run proportion (stationary distribution) of time that a person will be employed is $76.26 \%$, unemployed $4.38 \%$ and inactive $19.36 \%$.

\section{DISCUSSION}

The model developed using the Markov process techniques, allows us to calculate the long-run proportion of transitions, first-passage time which is considered as a key indicator of how fast the worker transits in a given labour market and the transition state probabilities. These parameters are then used to detect labour market failures and accordingly propose policies and procedures that Government can use to build a more efficient labour market and increase employability. Here, it is also important to note that the model can be applied only to countries that have panel data enough to compute model parameters, and that in this paper I focus on the movement of individual between states, not on its sources.

Labour market planning, implementing new reforms and policies are extremely important governmental actions in any country. Mainly the government is seen as formulating policies in response to a certain problem. Therefore, policy analysts and academia are being often required to give advice to policy makers. The goal of their complex analysis is to detect, and understand problems and suggest a way to help and improve government's performance.

In my paper, the results suggest that for workers the probability of remaining in the same labour market status is high, especially for inactive people, 0.82. Nonetheless, transitions from inactivity back into the labour market are relatively weak, i.e. 688 days to employment state and 1437 days to unemployment state. Most of the people who are neither in work nor seeking employment are discouraged, they do not believe there are any job available, or they do not want a job. Here I will quote, Theresa May, the pensions secretary back in 2010: "It's alarming that more and more people are giving up looking for a job altogether with record levels of economic inactivity."

Furthermore, the first passage time (FTP) matrix shows that 198 days or 6.6 mounts are needed for a transit from unemployed to employed state. All the numbers suggest that UK is fronting a long-term unemployment. This is a real problem, because in practice employers almost never consider hiring people unemployed longer than 6 months. In fact, they easily get excluded from the world of work and become permanent unemployed or discouraged.

This disconnection of the long-term unemployed workers from the labour market can permanently harm UK productivity capacity. Hence, it is a problem that can be solved by government intervention. Some of the interventions that the government can implement are: to start hiring the long-term unemployed people or start giving employer tax incentives if they hire long-term unemployed person.

Another important purpose of this assessment is to obtain more accurate estimation of future policy implementation expenses. Indeed, in the recent years it is noticed raising costs of these special interventions, and the expectation is that they will continue to grow. More details are given in a government publication titled "Europe 2020:UK National Reform Programme 2016". Thus, in order to predict the future expenses, policy makers need to be able to estimate precisely the evolution of a particular group of people (transition probability matrix), the time spent in various states (MST), and the time until the process first enters a given state (FTP). Let me restate that the traditional static labour market models can only estimate the stocks of workers found in a particular labour market states, but can't tell us nothing about their flow, waiting time and evolution. Therefore, it is important to model the dynamics via continuous-time Markov model. Besides the cost estimation, the result of this analysis, can be used in comparative analysis (between countries, different time periods), to analyze the impact of a certain reforms. For example, using the estimated transition probability matrix $P(0)$ and a built in fit function in the computer algebra package MATHEMATICA, the transition prediction matrix for year 2016 has been computed:

$$
\begin{aligned}
& \text { P8 }=N[\text { MatrixPower }[P(0), 8]] \\
& =\left[\begin{array}{ccc}
0.7817 & 0.0544 & 0.1638 \\
0.6960 & 0.0622 & 0.24179 \\
0.6056 & 0.068 & 0.32630
\end{array}\right]
\end{aligned}
$$

The probability of remaining in the same labour market status is expected to decrease, especially for inactive, from 0,82 to 0.33 .

Furthermore, by analyzing the dynamical behavior of the labour market, it is noticed that the continuous-time 
Markov model is able to estimate the true proportion of people, i.e. the percentage of employed, unemployed and inactive people. This is seen in Table 1. Here, the estimated long-run proportion is almost the same with the real market data taken from the Office of National Statistic of the UK.

Table 1. Long-run proportion vs Real market data

\begin{tabular}{|l|l|l|}
\hline Activity status & $\begin{array}{l}\text { Long-run } \\
\text { proportion, } \\
\text { stationary } \\
\text { distribution }\end{array}$ & $\begin{array}{l}\text { Real data } \\
\text { according to the } \\
\text { Office of } \\
\text { National } \\
\text { Statistics, Oct- } \\
\text { Dec 2016 }\end{array}$ \\
\hline Employed & $76.26 \%$ & \multicolumn{1}{|c|}{$76.0 \%$} \\
\hline Unemployed & $4.38 \%$ & $19.3 \%$ \\
\hline Inactive & $19.36 \%$ & \multicolumn{1}{|c|}{$19.3 \%$} \\
\hline
\end{tabular}

Source: data is retrieved from https://www.ons.gov.uk, Office of National Statistics

Thus, in Oct-Dec 2016 the UK labor market has reached its steady state, also known as a dynamical equilibrium. Now the system will tend to remain constant over time. In other words, if a system is in a steady state, then the recent UK labor market behavior will continue as it is in the future. But this steady state requires continuous care or activity to maintain, since the system has a higher level of energy than its surroundings. At the moment when external force, such as the great recession 2008, push the system out its equilibrium, the labor market will react to reach a new equilibrium after some time in a way.

\section{Acknowledgment}

The British Household Panel Survey (BHPS) data used in this paper, were made available through the UK Data Archive. The data were originally collected by the the ESRC UK Longitudinal Studies Centre (ULSC), together with the Institute for Social and Economic Research (ISER) at the University of Essex. Neither the original collectors of the data nor the Archive bear any responsibility for the analyses or interpretation presented here.

\section{REFERENCES}

Abowd, J. M., \&Zellner, A. (1985). Estimating gross labor-force flows. Journal of Business \& Economic Statistics, 3(3), 254-283.

Aoki, M., \& Yoshikawa, H. (2011). Reconstructing macroeconomics: a perspective from statistical physics and combinatorial stochastic processes. Cambridge University Press.

Bascetto, V., Moatti, J. P., Paraponaris, A., \&Sagaon Teyssier, L. (2009). A Continuous-time Markov Process for Mobility in the Labor Market: The Impact of Breast Cancer Diagnosis in the Case of French Females. mimeo, communication aux Journées des Economistes de la Santé Français, ENSAI, Bruz, 3-4 décembre.

Baussola, M., \&Mussida, C. (2011). The natural rate of unemployment and the unemployment gender gap. Department of Economic and Social Sciences, Catholic University of the Sacred Heart, Piacenza, Working Paper, (80).

Blanchard, O. J., \& Diamond, P. (1992). The flow approach to labor markets. American Economic Review, American Economic Association, vol. 82(2), pages 354359.

Blanchard, O. J., Diamond, P., Hall, R. E., \& Murphy, K. (1990). The cyclical behavior of the gross flows of US workers. Brookings Papers on Economic Activity, (2), 85155.

Bosch, M., \& Maloney, W. F. (2005). Labor market dynamics in developing countries: comparative analysis using continuous time Markov processes (Vol. 3583). World Bank Publications.

Burdett, K. and D. T. Mortenscn (1980). Search layoffs, and labor market equilibrium. Journal of Political Economy, 88,652-672.

Clark, K. B., Summers, L. H., Holt, C. C., Hall, R. E., and Baily, M. N. (1979). Labor market dynamics and unemployment: a reconsideration. Brookings Papers on Economic Activity, 1979(1), 13-72.

Coleman, J. S. (1984). Introducing social structure into economic analysis. The American Economic Review, 74(2), 84-88.

Davis, S. J., \&Haltiwanger, J. (1990). Gross job creation and destruction: Microeconomic evidence and macroeconomic implications. In NBER Macroeconomics Annual 1990, Volume5, p. 123-186, MIT Press.

Elsby, M., Solon, G., Michaels, R., (2009). The ins and outs of cyclical unemployment. American Economic Journal: Macroeconomics, 1 (1), 84-110.

Fabrizi, E., \&Mussida, C. (2009). The determinants of labour market transitions. Giornaledegli Economisti $e$ Annali di Economia, 68(2), 233-265.

Flinn, C., \& Heckman, J. (1982b). New methods for analyzing structural models of labor force dynamics. Journal of Econometrics, 18(1), 115-168.

Fougere, D., \&Kamionka, T. (2003). Bayesian inference for the mover-stayer model in continuous time with an application to labour market transition data. Journal of Applied Econometrics, 18(6), 697-723. 
19 N. Spaseski/ Southeast Europe Journal of Soft Computing Vol.6 No.1 March 2016 (13-19)

Fujiwara, Y., \& Aoyama, H. (2010). A Stochastic Model of Labor Productivity and Employment. RIETI Discussion Papers, 10-E-001, available online: http://www.rieti.go.jp/jp/publications/dp/10e001.pdf

Hall, R. E. (2005). Employment efficiency and sticky wages: Evidence from flows in the labor market. Review of Economics and statistics, 87(3), 397-407.

Marston, S. T., Feldstein, M., \& Hymans, S. H. (1976). Employment instability and high unemployment rates. Brookings Papers on Economic Activity, 1976(1), 169210.

Mincer, J. (1966). Labour-force participation and unemployment: A review of recent evidence, in: Gordon, R.A. and M.S. Gordon (Eds.), Prosperity and Unemployment, New York: John Wiley.

Mortensen, D. T., \& Neumann, G. R. (1984). Choice or chance? A structural interpretation of individual labor market histories. In Studies in labor market dynamics (pp. 98-131). Springer Berlin Heidelberg.

Mortensen, D. T., \&Pissarides, C. A. (1994). Job creation and job destruction in the theory of unemployment. The review of economic studies, 61(3), 397-415.

Petrongolo, B., \&Pissarides, C. A. (2008). The ins and outs of European unemployment. The American Economic Review, 98(2), 256-262.

Pissarides, C. (1986). Unemployment and vacancies in Britain. Economic policy, 1(3), 499-541.

Pissarides, C. A. (1991). Real wages and unemployment in Australia. Economica, London School of Economics and Political Science, vol. 58(229), pages 35-55.

Schettkat, R. (Ed.). (2003). The flow analysis of labour markets. Routledge: London.

Shimer, R. (2005). The cyclical behavior of equilibrium unemployment and vacancies. The American Economic Review, 95(1), 25-49.

Shimer, R. (2007). Mismatch. The American Economic Review, 97(4), 1074-1101.

Smit, J. (1955). The spontaneous Hall effect in ferromagnetics I. Physica, 21(6-10), 877-887.

Tiongson, E. R., \& Fares, J. (2007). Youth unemployment, labor market transitions, and scarring: evidence from Bosnia and Herzegovina, 2001-04. Policy Reaserch Working Paper Series 4183. Washington, DC: World Bank.
Toikka, R. S. (1976). A Markovian model of labor market decisions by workers. The American Economic Review, Vol. 66, No. 5, 821-834.

University of Essex. Institute for Social and Economic Research. (2010). British Household Panel Survey: Waves 1-18, 1991-2009. [data collection]. 7th Edition. UK Data Service. SN: 5151, http://doi.org/10.5255/UKDA-SN5151-1.

Weiner, M. (1982). International Migration and Development: Indians in the Persian Gulf. Population and Development Review, 8 (1). 1-36. 